\title{
Estimation of Body Composition and Normal Fluid Status Using a Calf Bioimpedance Technique
}

\author{
Fansan Zhu Nathan W. Levin \\ Renal Research Institute, New York, N.Y., USA
}

\author{
Key Words \\ Calf bioimpedance $\cdot$ Body composition $\cdot$ Normal fluid \\ status · Dialysis
}

\begin{abstract}
The aims of this study in hemodialysis (HD) patients were: 1 . To evaluate the relationship of calf bioimpedance with total body composition and fluid status as measured by gold standard methods. 2. To investigate the ability of calf normalized resistivity (CNR) to predict the normal fluid status (dry weight: DW) in a prospective study. In the body composition study $(n=41)$, fluid status $\left(E_{C V} V_{B r} / F F M_{M R I}\right)$, muscle mass $\left(M_{M R I}\right)$, and total adipose tissue (TAT $\left.T_{M R I}\right)$ were measured by dilution $\left(\mathrm{D}_{2} \mathrm{O}\right.$ and $\mathrm{Br}$ ) and $\mathrm{MRI}$ methods three hours prior to HD treatment. Calf extracellular and intracellular resistance, resistivity, and CNR were measured with a multi-frequency bioimpedance device (Hydra 4200). In the fluid status study ( $n=32$ with 429 measurements), a nonlinear model based on the differences in CNR between patients and healthy subjects was established to predict $D_{\text {CBIS }}$ previously determined by a separate continuous calf bioimpedance spectroscopy (CBIS) method. CNR significantly correlated with a gold standard hydration marker $\left(\mathrm{ECV}_{\mathrm{Br}} / \mathrm{FFM}_{\mathrm{MRI}}\right)$. Calf body composition models were highly correlated with $M_{M R I}$ $\left(R^{2}=0.85\right)$ and $T_{A T} T_{M R I}\left(R^{2}=0.85\right)$. $D_{\text {CBIS }}$ prediction was validated with a CNR model in the degree of differences of $0.94 \pm 0.18,0.39 \pm 0.7$ and $-0.02 \pm 0.8 \mathrm{~kg}$ from $D_{\text {CBIS }}$ when post HD fluid overload was $1.8 \pm 1.2,1.15 \pm 0.8$ and $0.54 \pm$
\end{abstract}

(C) 2015 S. Karger AG, Basel

0253-5068/15/0393-0025\$39.50/0
$0.5 \mathrm{~kg}$, respectively. These differences are not considered to be clinically significant. Conclusion: This practical method of calf bioimpedance is useful to predict body composition and normal fluid status in dialysis patients.

(C) 2015 S. Karger AG, Basel

\section{Introduction}

The estimation of the normal fluid status (dry weight) in hemodialysis (HD) patients is a significant problem because of lack of understanding of the physiological concept of dry weight and of appropriate techniques to measure fluid status accurately and precisely [1]. Bioimpedance techniques (BIT) are useful in the management of fluid status in routine dialysis $[2,3]$. BIT application in clinical studies include whole body, single-frequency bioimpedance vector analysis (BIVA) [4], whole body multifrequency bioimpedance spectroscopy (wBIS) [5], and calf bioimpedance spectroscopy (cBIS) [6], each with individual benefits and limitations $[7,8]$. Whole body (wrist to ankle) techniques using four electrodes are widely used with acceptable accuracy for subjects in fluid equilibrium and with normal body composition [9-11]. However, the accuracy is affected when fluid distribution changes between body segments or variably by body composition as reflected by body mass index (BMI) $[12,13]$.

Continuous intradialytic calf bioimpedance spectroscopy (cBIS) has been used to determine dry weight 
Table 1. Correlation of bioimpedance parameters and body composition $(n=41) r^{2}$ ( $p$ value)

\begin{tabular}{lccllll}
\hline & $\operatorname{SAT}_{\mathrm{MRI}}(\mathrm{kg})$ & $\mathrm{MM}_{\mathrm{MRI}}(\mathrm{kg})$ & $\mathrm{TBW}_{\mathrm{D}_{2} \mathrm{O}}(\mathrm{l})$ & $\mathrm{ECV}_{\mathrm{Br}}(\mathrm{l})$ & $\mathrm{ICV}_{\mathrm{TBK}}(\mathrm{l})$ & $\mathrm{ECV}_{\mathrm{Br}} / \mathrm{FFM}_{\mathrm{MRI}}(\mathrm{l} / \mathrm{kg})$ \\
\hline $\mathrm{cRe}(\Omega)$ & $0.09(0.06)$ & $0.04(0.2)$ & $0.14(<0.05)$ & $0.11(<0.05)$ & $0.02(0.3)$ & $0.05(0.2)$ \\
$\mathrm{cRi}(\Omega)$ & $0(0.9)$ & $0.24(<0.001)$ & $0.11(<0.05)$ & $0.04(0.2)$ & $0.33(<0.0001)$ & $0.15(0.2)$ \\
$\operatorname{Rho}(\Omega \mathrm{cm})$ & $0.21(<0.01)$ & $0.25(0.0001)$ & $0.01(0.1)$ & $0.04(0.2)$ & $0.26(0.0001)$ & $0.05(0.2)$ \\
$\mathrm{CNR}\left(\Omega \cdot \mathrm{m}^{3} / \mathrm{kg}\right)$ & $0.01(0.6)$ & $0.02(0.3)$ & $0.01(0.5)$ & $0.02(0.4)$ & $0.07(0.1)$ & $0.12(<0.05)$ \\
Calf circumference $(\mathrm{cm})$ & 0.13 & 0.53 & 0.36 & 0.28 & 0.5 & 0 \\
P value & $<0.05$ & $<0.0001$ & $<0.0001$ & $<0.01$ & $<0.0001$ & 0.9 \\
\hline
\end{tabular}

( $\left.\mathrm{DW}_{\mathrm{cBIS}}\right)$ as defined by two criteria: (1) when the curve of the ratio of calf extracellular resistance (cRe) at the beginning $\left(\mathrm{cRe}_{0}\right)$ to the $c R e$ at any time $\left(\mathrm{cRe}_{\mathrm{t}}\right)$ during HD becomes and remains flat (change $<1 \%$ of $c \mathrm{Re}_{0} / \mathrm{cRe}_{\mathrm{t}}$ ) during twenty minutes of continuing dialysis; and (2) an increase of calf normalized resistivity (CNR) to the threshold of the range in the healthy population $\left(18.5\left(10^{-2} \cdot \Omega \cdot \mathrm{m}^{3} / \mathrm{kg}\right)\right.$ for males and $19.2\left(10^{-2} \cdot \Omega \cdot \mathrm{m}^{3} / \mathrm{kg}\right)$ for females $)$ [6]. The cBIS measurement is not affected by fluid distribution or body composition because the continuous measurement of only one segment reflects relative changes in resistance. $\mathrm{CNR}$ is also not affected because of normalization by BMI $[14,15]$. However, this method has limitations, including inconvenience for dialysis patients due to the requirement of constant body position during the entire treatment [16]. In addition, it has not been demonstrated how calf measurement represents total body fluid status.

The aims of this study were to: (1) Evaluate the relationship of calf bioimpedance measurement with body composition and fluid status measured by isotope dilution $\left(\mathrm{D}_{2} \mathrm{O}\right.$ and $\left.\mathrm{Br}\right)$, total body potassium (TBK) and magnetic resonance imaging (MRI) methods. (2) Investigate in a validation study whether CNR can be used to predict $\mathrm{DW}_{\mathrm{cBIS}}$ as an alternative to the continuous intradialytic method.

\section{Methods}

The study protocols for the two separate studies were approved by the IRB of Beth Israel Medical Center. All patients gave signed consent.

\section{Study 1}

At least three hours prior to HD treatment, total body water $\left(\mathrm{TBW}_{\mathrm{D}_{2} \mathrm{O}}\right)$ and extracellular fluid volume $\left(\mathrm{ECV}_{\mathrm{Br}}\right)$ were measured by the dilution of deuterium and bromide, respectively and intracellular fluid volume ( $\mathrm{ICV}_{\text {Твк }}$ ) by total body potassium (TBK) [17]. Muscle mass $\left(\mathrm{MM}_{\mathrm{MRI}}\right)$ and total adipose tissue $\left(\mathrm{TAT}_{\mathrm{MRI}}\right)$ were estimated by MRI. Fat free mass $\left(\mathrm{FFM}_{\mathrm{MRI}}\right)$ is defined as the difference between body weight and $\mathrm{TAT}_{\mathrm{MRI}}$. The gold standard hydration marker is represented by $\mathrm{ECV}_{\mathrm{Br}} / \mathrm{FFM}_{\mathrm{MRI}}$ pre $\mathrm{HD}$ and post $\mathrm{HD} \mathrm{ECV} \mathrm{Er}_{\mathrm{Br}} / \mathrm{FFM}_{\mathrm{MRI}}$ is calculated by a known ultrafiltration volume (see appendix). Calf bioimpedance spectroscopy (cBIS) was performed with subjects in a supine position using a multifrequency $(5-1,000 \mathrm{kHz})$ device (Hydra 4200) pre- and post-HD. Calf extracellular (cRe) and intracellular $(\mathrm{cRi})$ resistances were obtained with the Cole model [18]. Calf resistance $\left(\mathrm{cR}_{5}\right)$ at $5 \mathrm{kHz}$, calf resistivity (Rho), CNR and calf cross-sectional area were calculated [19]. Equations for calculating calf parameters are shown in the appendix. Calf bioimpedance parameters are used to establish the model to estimate body hydration and body composition.

\section{Study 2}

Study 2 target post-HD weight was prescribed at baseline (BL); $\mathrm{DW}_{\mathrm{CBIS}}$ was determined by the two criteria described above with the continuous cBIS technique using a modified Xitron device (frequency range from 1 to $300 \mathrm{kHz}$ ) [6]. The target post $\mathrm{HD}$ weight was reduced by $0.2-0.3 \mathrm{~kg}$ for each treatment until $\mathrm{DW}_{\mathrm{cBIS}}$ was attained. In this paper, we focus on whether the $\mathrm{DW}_{\mathrm{CBIS}}$ can be predicted using post HD CNR only in patients with varying degrees of fluid overload (FO). Total fluid overload (TFO) was defined as the difference between post $\mathrm{HD}$ weight at the start of the study $(\mathrm{BL})$ and $\mathrm{DW}_{\mathrm{cBIS}}$. In order to analyze the effect of $\mathrm{FO}$ on the accuracy of prediction of $\mathrm{DW}_{\mathrm{CBIS}}$, TFO was divided into four stages: stage $1(\mathrm{BL})$, and stages 2,3 , and $4\left(\mathrm{DW}_{\mathrm{cBIS}}\right)$ with each stage representing one third of the TFO [15]. Ten of thirty-two patients were studied to develop a model to predict $\mathrm{DW}_{\mathrm{cBIS}}$ by $\mathrm{CNR}$ based on the relationship between change in CNR and change in weight from $\mathrm{BL}$ to $\mathrm{DW}_{\mathrm{cBIS}}$. In the other 22 patients, the developed model was applied to validate its ability to predict $\mathrm{DW}_{\mathrm{cBIS}}$. Systolic (SBP), diastolic (DBP) blood pressure, and heart rate (HR) were recorded pre- and post-HD.

Data are presented with mean \pm SD. The difference in parameters between stages was identified using the ANOVA analysis by GraphPad Prism 5. The multiple regression model based on calf bioimpedance measurement for estimating body composition was established by SYSTAT13. A p value less than 0.05 was considered significant.

\section{Results}

\section{Study 1}

$\mathrm{N}=41,23 \mathrm{~m}$, age $54.7 \pm 11$ years; no calf bioimpedance parameters correlated with the gold standard hydration marker $\mathrm{ECV}_{\mathrm{Br}} / \mathrm{FFM}_{\mathrm{MRI}}$ except CNR (table 1 and fig. 1). 
Fig. 1. Correlation of CNR to the degree of fluid status (a) pre-HD and (b) post-HD.
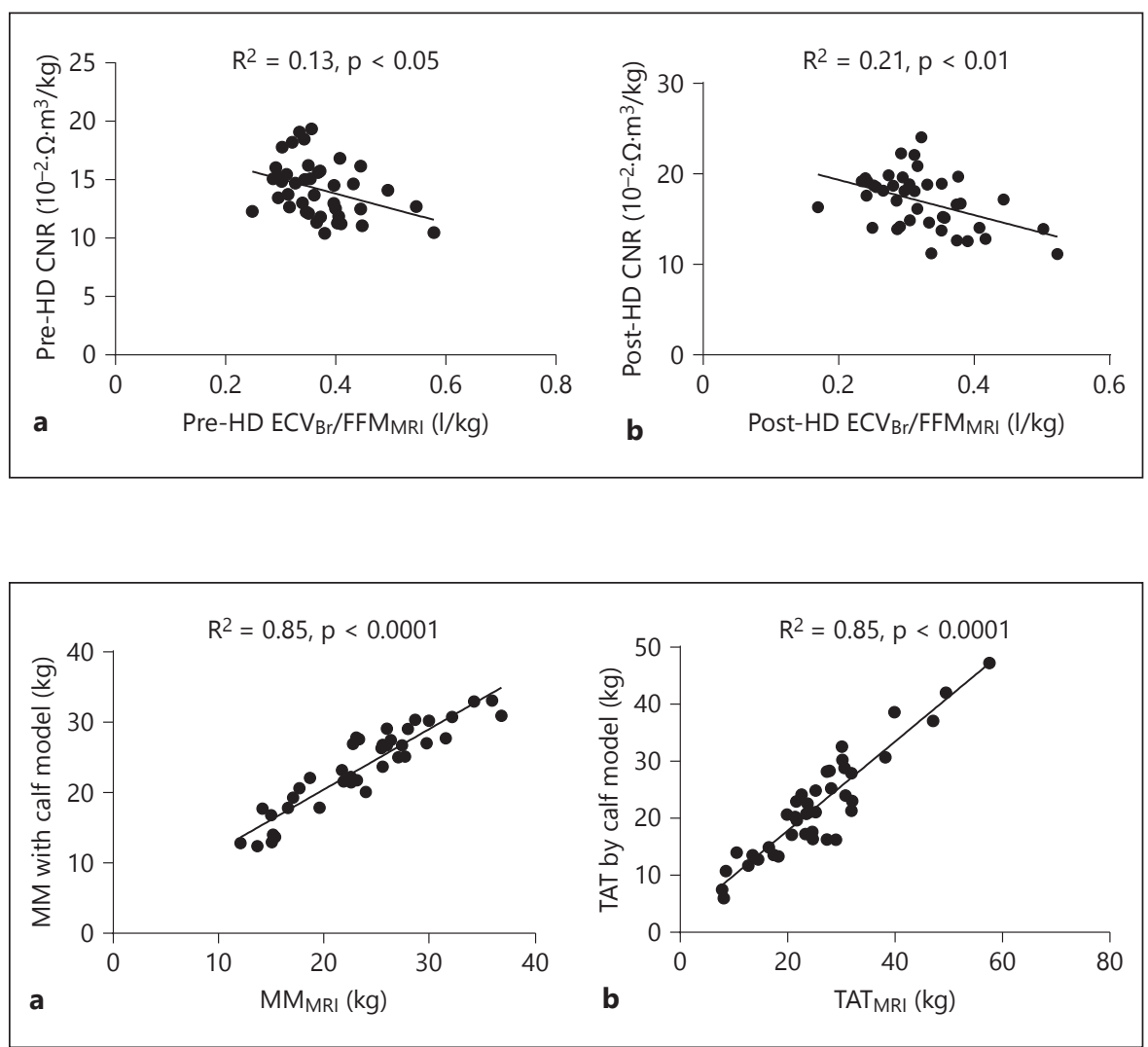

Fig. 2. Estimation of muscle mass (MM) (a) and total body adipose tissues (TAT) (b) with calf bioimpedance model (CBM) show: $\mathrm{MM}_{\mathrm{CBM}}=-0.103 * \mathrm{cRi}+30.58 *$ Height $+0.159 *$ weight $-0.098 *$ Age 28.736, and $\mathrm{TAT}_{\mathrm{CBM}}=0.13 * \mathrm{cRi}-0.142 *$ $\mathrm{CA}+2.43 * \mathrm{BMI}+0.129 *$ Age -44.33 , where cRi is calf intracellular resistance $(\Omega)$, Height is body height $(\mathrm{m})$ and weight (kg). CA is average calf cross-sectional area $\left(\mathrm{cm}^{2}\right)$; BMI is body mass index $\left(\mathrm{kg} / \mathrm{m}^{2}\right)$.
Fig. 3. Correlation of BMI to total adipose tissue (TAT) (a) and to muscle mass (b) pre HD measurement, where TAT and muscle mass were measured by MRI.

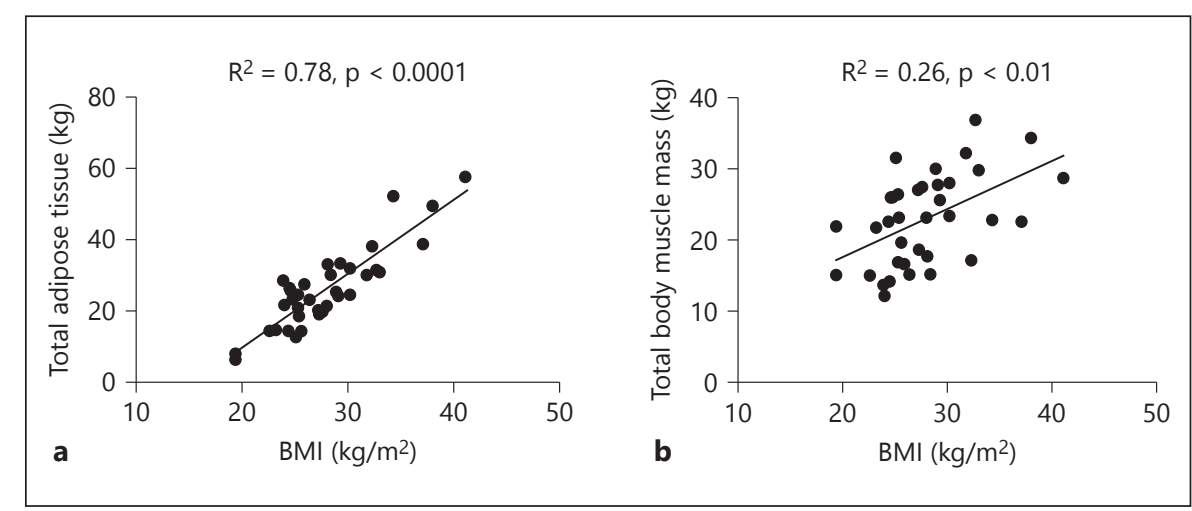

Pre-HD calf extracellular resistance (cRe) significantly correlated with $\mathrm{TBW}_{\mathrm{D} 2 \mathrm{O}}$ and $\mathrm{ECV}_{\mathrm{Br}}$ and $\mathrm{cR}_{5}$ with $\mathrm{TBW}_{\mathrm{D} 2 \mathrm{O}}$ only while calf intracellular resistance (cRi) correlated with $\mathrm{MM}_{\mathrm{MRI}}$ and TBK ( $\left.\mathrm{ICV}_{\mathrm{TBK}}\right)$. The correlation between $\mathrm{CNR}$ and $\mathrm{ECV}_{\mathrm{Br}} / \mathrm{FFM}_{\mathrm{MRI}}$ was greater post-HD $\left(\mathrm{R}^{2}=0.21, \mathrm{p}<0.01\right)$ than pre HD $\left(\mathrm{R}^{2}=0.13, \mathrm{p}<0.05\right)$. Calf circumference correlated significantly with all parameters of body composition but did not correlate with the $\mathrm{ECV}_{\mathrm{Br}} / \mathrm{FFM}_{\mathrm{MRI}}$. The calf body composition model $(\mathrm{CBM})$ was used to calculate $\mathrm{TAT}_{\mathrm{CBM}}$ and $\mathrm{MM}_{\mathrm{CBM}}$, which correlated highly with $\mathrm{TAT}_{\mathrm{MRI}}\left(\mathrm{R}^{2}=0.85, \mathrm{p}<0.0001\right)$ and $\mathrm{MM}_{\mathrm{MRI}}\left(\mathrm{R}^{2}=0.85, \mathrm{p}<0.0001\right)$, respectively (fig. $2 \mathrm{a}$ and b). BMI strongly correlated $\left(\mathrm{R}^{2}=0.78, \mathrm{p}<0.0001\right)$ with TAT $_{\text {MRI }}$ but weakly $\left(\mathrm{R}^{2}=0.26, \mathrm{p}<0.01\right)$ with $\mathrm{MM}_{\mathrm{MRI}}$ (fig. 3a and b).

\section{Study 2}

$\mathrm{N}=32,16 \mathrm{~m}, 53.1 \pm 15$ years (429 measurements and $13.4 \pm 8.9$ measurements per patient). The average $\mathrm{FO}$ in the development model $(\mathrm{n}=10)$ was $\mathrm{FO}_{\mathrm{BL}}=3.01 \pm 1 \mathrm{~kg}$, 
Fig. 4. a Prediction of fluid overload by calf model (establishing model, $\mathrm{n}=10$ ) in different stages. b Prediction of fluid overload by calf model (validation model, $\mathrm{n}=22$ ) in different stages.

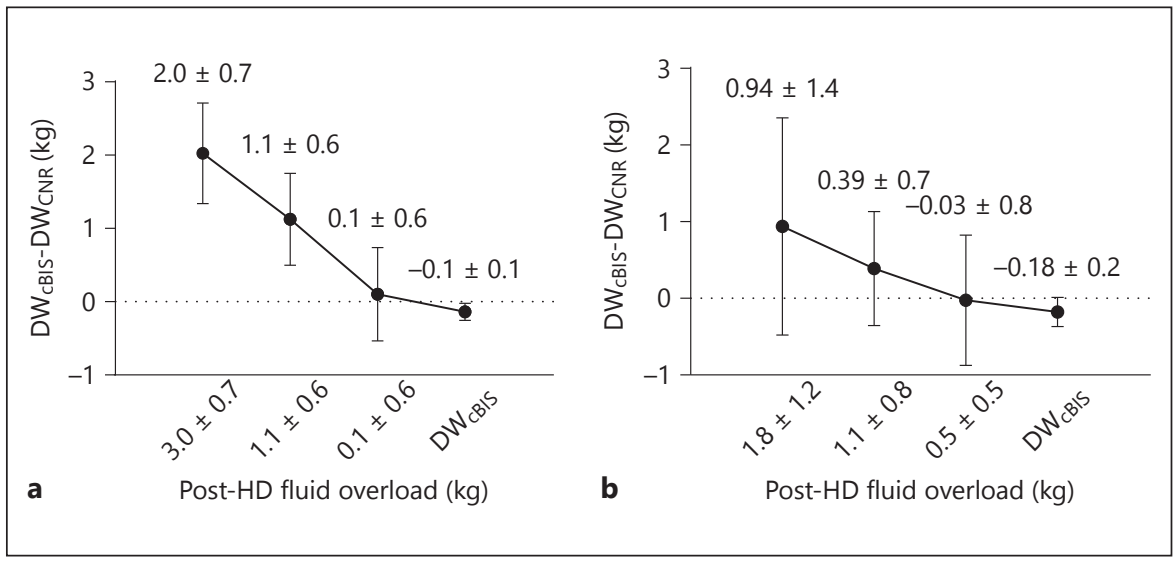

Table 2. Summary of results in validation patients $(n=32)$

\begin{tabular}{|c|c|c|c|c|c|}
\hline Fluid overload $(\mathrm{FO})^{\mathrm{a}}$, kg & $2.2 \pm 1.3$ & $1.5 \pm 0.9$ & $0.7 \pm 0.5$ & 0 & $<0.0001$ \\
\hline Post-HD Wt (DW $\left.{ }_{\mathrm{cBIS}}\right), \mathrm{kg}$ & $73 \pm 15.7$ & $72.2 \pm 15.5$ & $71.5 \pm 15.5$ & $70.8 \pm 15$ & $<0.0001$ \\
\hline Pre-HD Wt, kg & $75.7 \pm 16.1$ & $74.8 \pm 15.7$ & $74.2 \pm 15.8$ & $73.3 \pm 16$ & $<0.0001$ \\
\hline Pre-HD CNR $\left(10^{-2} \cdot \Omega \cdot \mathrm{m}^{3} / \mathrm{kg}\right)$ & $14.9 \pm 2.8$ & $15.3 \pm 3.5$ & $15.3 \pm 3$ & $17.1 \pm 2.6$ & $<0.0001$ \\
\hline Post-HD CNR $\left(10^{-2} \cdot \Omega \cdot \mathrm{m}^{3} / \mathrm{kg}\right)$ & $18.6 \pm 3.9$ & $19.4 \pm 5.1$ & $19.7 \pm 4$ & $21.7 \pm 3.3$ & $<0.0001$ \\
\hline Pre-HD HR, beats/min & $77.9 \pm 13.3$ & $77.6 \pm 11.6$ & $77.5 \pm 25$ & $80.4 \pm 12$ & 0.27 \\
\hline Post-HD SBP, mm Hg & $121.5 \pm 24$ & $123.3 \pm 24$ & $116.9 \pm 17$ & $121.8 \pm 22$ & 0.22 \\
\hline Post-HD DBP, mm Hg & $70.7 \pm 16.5$ & $71.5 \pm 16$ & $70.5 \pm 17$ & $72.2 \pm 15$ & 0.85 \\
\hline Post-HD HR, beats/min & $82.4 \pm 11$ & $80.2 \pm 12$ & $81.2 \pm 12$ & $82.1 \pm 11$ & 0.68 \\
\hline FO-CNR, kg & $0.89 \pm 0.9$ & $0.82 \pm 0.7$ & $0.65 \pm 0.7$ & $0.16 \pm 0.17$ & $<0.0001$ \\
\hline DW-CNR, kg & $72.1 \pm 15$ & $71.4 \pm 15$ & $70.8 \pm 15$ & $70.6 \pm 15$ & $<0.0001$ \\
\hline
\end{tabular}

${ }^{\text {a }} \mathrm{FO}$ is defined as the difference between $\mathrm{DW}_{\mathrm{cBIS}}$ and post $\mathrm{HD}$ weight at different stages.

$\mathrm{FO}_{\text {Stage } 2}=2.1 \pm 0.7 \mathrm{~kg}, \mathrm{FO}_{\text {Stage } 3}=0.96 \pm 0.5 \mathrm{~kg}$, and $\mathrm{FO}_{\mathrm{DW}} \mathrm{CBIS}=0$ and in the validation model $(\mathrm{n}=22)$ was: $\mathrm{FO}_{\mathrm{BL}}=1.8 \pm 1.2 \mathrm{~kg}, \mathrm{FO}_{\text {Stage } 2}=1.15 \pm 0.8 \mathrm{~kg}, \mathrm{FO}_{\text {Stage3 }}=$ $0.54 \pm 0.5 \mathrm{~kg}$, and $\mathrm{FO}_{\mathrm{DW}_{\mathrm{CBIS}}}=0$, respectively. Change in CNR significantly correlated at stage $1\left(\mathrm{R}^{2}=0.33, \mathrm{p}<\right.$ $0.001)$, stage $2\left(R^{2}=0.36, p<0.001\right)$ post-HD except at stage 3 where weight differences were small $(0.54 \pm 0.51)$. Blood pressure and heart rate did not differ significantly either pre or post HD during the study. However, SBP was low at BL (table 2).

The CNR nonlinear model for predicting dry weight was developed by best fitting experimental data in 10 patients as follows:

$$
\begin{aligned}
& \mathrm{FO}_{\mathrm{CNR}}=\mathrm{k} * \exp \left[-\left(\mathrm{CNR}_{\mathrm{P}}-\mathrm{CNR}_{\mathrm{H}}\right)^{\mathrm{n}}\right] \\
& \mathrm{DW}_{\mathrm{CNR}}=\text { Post } \mathrm{Wt}-\mathrm{FO}_{\mathrm{CNR}}
\end{aligned}
$$

where $\mathrm{k}=0.35$ in unit of $1 / \Omega \cdot \mathrm{m}^{3} / \mathrm{kg}, \mathrm{n}=1 / 3$ were obtained by the method of least error from the previously independently determined $\mathrm{DW}_{\mathrm{cBIS}} ; \mathrm{CNR}_{\mathrm{P}}$ and $\mathrm{CNR}_{\mathrm{H}}$ represent measurement in patients, and the threshold of the normal range in healthy subjects, respectively. The thresholds are $18.5\left(10^{-2} \cdot \Omega \cdot \mathrm{m}^{3} / \mathrm{kg}\right)$ in males and 19.1 $\left(10^{-2} \cdot \Omega \cdot \mathrm{m}^{3} / \mathrm{kg}\right)$ in females, respectively [19]. Figure $4 \mathrm{a}$ shows the difference between $\mathrm{DW}_{\mathrm{CNR}}$ as predicted by the model and the $\mathrm{DW}_{\mathrm{cBIS}}$; figure $4 \mathrm{~b}$ shows the results with 22 remaining patients in the application of this model (validation).

The difference between prediction and actual $\mathrm{DW}_{\mathrm{cBIS}}$ by the CNR model decreased $(\mathrm{p}<0.0001)$ with reduction of fluid overload over stages (table 2). Bland-Altman analysis showed $\mathrm{DW}_{\mathrm{cBIS}}$ was overestimated by $2.03 \pm 0.69,1.13 \pm 0.63$, and $0.1 \pm 0.641$ and by $0.94 \pm$ 

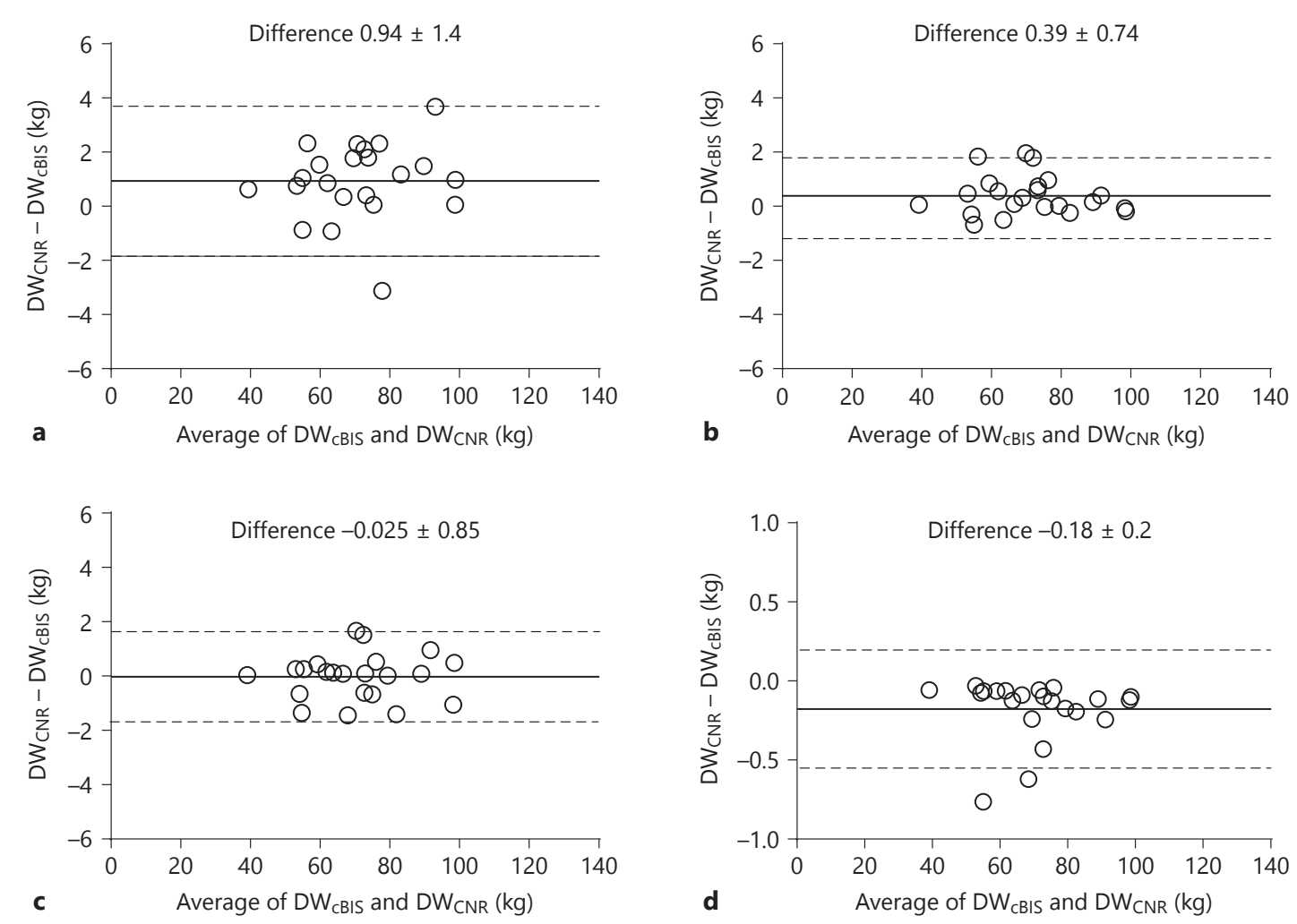

Fig. 5. Bland-Altman analysis for comparing predicted DW with CNR and DWcBIS in BL (a), stage 2 (b), stage 3 (c) and the last stage (d) $\mathrm{DW}_{\mathrm{cBIS}}$ in the validation group $(\mathrm{n}=22)$.

$0.18,0.39 \pm 0.7$, and $-0.02 \pm 0.81$ with the establishing model and validating model at three stages of FO, respectively (fig. 5).

\section{Discussion}

This original work shows two separate applications of calf bioimpedance: (1) its relationship with body composition as measured by gold standard dilution and MRI techniques. (2) development of a model to predict normal fluid status using an independent method (CNR) to initially establish the latter.

\section{Why use Calf Measurements?}

The fundamental requirement for accuracy of bioimpedance measurements is that the subject should be made of a cylinder with homogeneous conductivity in cross-sectional area [20]. Practically, we assume that the whole body can be modeled as an approximately ideal cylinder with uniform body composition so that distribution of current density is nearly identical in all cross-sectional areas. However, the equivalent resistance or impedance of this ideal cylinder can be altered significantly when distribution of fluid is changed between segments even when the actual fluid volume or body weight is unchanged [21-23].

The calf, however, as one segment of the body, provides an approximate cylinder with uniform body composition. In this study, calf circumference correlated with all total body components (table 1). These relationships make it possible to use one segment (calf) to predict total body fluid, fluid status, and body composition. For example, the correlation of the calf models with $\mathrm{MM}_{\mathrm{MRI}}$ is $\mathrm{R}^{2}=0.85$ and with $\mathrm{TAT}_{\mathrm{MRI}}$ is also $\mathrm{R}^{2}=0.85$, which is much higher than it is with calf circumference, presumably, because the model includes intracellular calf resistance and body weight and height.

\section{Why use CNR and not Volume-Related Parameters?}

To compare fluid status in a population using absolute fluid volume is impossible because volume depends on body size and body composition partially related to 
fluid status. The CNR is the only parameter that correlates with the gold standard hydration marker $\left(\mathrm{ECV}_{\mathrm{Br}} / \mathrm{FFM}_{\mathrm{MRI}}\right)$ and this is not influenced by the body composition so that this correlation is the basis of the model to describe the relationship between change in fluid volume and change in CNR using a nonlinear model to predict the normal fluid status. In addition, the correlation of CNR with $\mathrm{ECV}_{\mathrm{Br}} / \mathrm{FFM}_{\mathrm{MRI}}$ post $\mathrm{HD}$ was better than pre-HD, which implies that the degree of hydration influence this relationship possibly because of segmental fluid distribution accompanying fluid overload.

\section{Prediction of Dry Weight with a Nonlinear Model}

This model has been established based on an exponential function of differences in CNR in individual patients, decreasing the levels of $\mathrm{FO}$ over time, FO, and the normal threshold of CNR. As fluid overload decreases, the difference between predicted $\mathrm{DW}_{\mathrm{CNR}}$ and $\mathrm{DW}_{\mathrm{cBIS}}$ was gradually reduced (fig. 4). This phenomenon may be explained by the shift of excess fluid from the intracellular to extracellular space during each stage of reduction of fluid overload.

Two major questions in clinical fluid management are: (1) how to determine normal fluid status (DW) and (2) how to reach the DW. Since treatment times in U.S. dialysis units are somewhat shorter than $4 \mathrm{~h}$, a relatively high UFR is often used in order to remove interdialytic fluid gain with risk of hypotension before DW is attained [24]. Methods such as increase in dialysis time or frequency combined with excellent control of salt intake would be good strategies to help patients retain normal fluid status.

\section{Limitations of the Study}

The number of patients in the dry weight study was small. The use of $\mathrm{DW}_{\mathrm{cBIS}}$ for the estimation of DW needs a larger clinical study for further validation. The new model needs testing in a large variety of clinical dialysis situations.

\section{Conclusion}

This study demonstrates that calf bioimpedance is useful to predict body composition and normal fluid status (dry weight). Prediction of dry wright $\left(\mathrm{DW}_{\mathrm{CNR}}\right)$ with the calf normalized resistivity (CNR) model provides a new tool to manage fluid status in dialysis patients as well as in CKD patients.

\section{Acknowledgments}

The authors thank the staff at Roosevelt-St. Luke Hospital for performing the isotope dilutions, TBK and MRI measurements. We greatly appreciate the work of colleagues and research fellows who have participated in dry weight and body composition studies over time.

\section{Disclosures}

Dr. Levin holds stock in Fresenius Medical Care.

\section{Appendix}

\section{CNR Calculation}

Resistivity calculation

$R h o=\frac{R \cdot A}{L}$,

where $\mathrm{R}(\Omega)$ is resistance at $5 \mathrm{kHz}$, which was extracted from the spectroscopic data, $L(10 \mathrm{~cm})$ is the length of measurement of segment, and $\mathrm{A}\left(\mathrm{cm}^{2}\right)$ is the average calf cross-sectional area. A can be calculated by calf circumference as follows:

$$
A=\pi r^{2}=\frac{\left(C_{\text {Max }}+C_{\text {Min }}\right)^{2}}{16 \pi} .
$$

where $\mathrm{C}_{\mathrm{Max}}$ and $\mathrm{C}_{\mathrm{Min}}$ are maximal and minimal circumferences at the sections of two measuring electrodes and $\mathrm{r}=\left(\mathrm{C}_{\mathrm{Max}}+\right.$ $\left.\mathrm{C}_{\text {Min }}\right) /(4 \pi)$. Then resistivity can be presented by

$$
R h o=\frac{R \cdot\left(C_{\text {Max }}+C_{\text {Min }}\right)^{2}}{16 \pi \cdot L} .
$$

Calf normalized resistivity (CNR) is defined as

$$
C N R=\text { Rho } / B M I \text {. }
$$

where BMI (body mass index) is body mass $(\mathrm{M}, \mathrm{kg}$ ) divided by body height square $\left(\mathrm{H}^{2}, \mathrm{~m}^{2}\right)$.

$$
C N R=\frac{R \cdot\left(C_{M a x}+C_{M i n}\right)^{2}}{16 \pi \cdot L}\left(\frac{H^{2}}{M}\right) .
$$

In Eq $\mathrm{A}-5$, unit of $\mathrm{C}_{\mathrm{Max}}, \mathrm{C}_{\mathrm{Min}}$, and $\mathrm{L}$ is in $\mathrm{cm}$ but $\mathrm{H}$ is in $\mathrm{m}$ and $\mathrm{M}$ in unit of $\mathrm{kg}$, so unit of CNR is $\left[10^{-2} \cdot \Omega \cdot \mathrm{m}^{3} / \mathrm{kg}\right]$. Since $\mathrm{m}^{3} / \mathrm{kg}=1 /\left(\mathrm{kg} / \mathrm{m}^{3}\right)$ is inverse of density, the CNR unit can be explained as ohm per density.

\section{Estimation of Body Composition using Calf Bioimpedance}

$$
\begin{aligned}
\mathrm{MM}_{\mathrm{CBM}}= & -0.103 * \mathrm{cRi}+30.58 * \text { Height }+0.159 * \text { Weight }- \\
& 0.098 * \mathrm{Age}-28.736, \\
\mathrm{TAT}_{\mathrm{CBM}}= & 0.13 * \mathrm{ARi}-0.142 * \mathrm{CA}+2.43 * \mathrm{BMI}+0.129 * \text { Age } \\
& -44.33
\end{aligned}
$$

where $\mathrm{cRi}$ is calf intracellular resistance $(\Omega)$, height is body height $(\mathrm{m})$, weight is body mass $(\mathrm{kg})$, and CA is calf cross-sectional area $\left(\mathrm{cm}^{2}\right)$.
Zhu/Levin 
The post-HD gold standard hydration marker was defined as $\left(\mathrm{ECV}_{\mathrm{Br}}-\mathrm{UFV}\right)$ / (Post HD Wt-TAT $\mathrm{MRI}$ ), where UFV is ultrafiltration volume in liter.

\section{Prediction of Normal Fluid Status with the CNR Model}

The ratio of change in total body extracellular fluid volume $(d(w E C V))$ to change in calf ECV is assumed to be proportional when fluid is reduced to normal fluid status. This process can be described as follows:

$$
\frac{d(w E C V)}{d(c E C V)}=k_{1},
$$

where $\mathrm{k}$ is a non-dimensional constant. The equation A-8 can be rewritten as:

$$
d(w E C V)=k_{1} * d(c E C F) .
$$

Integrating both sides the solution to the above equation (A-9) is: $\triangle w E C V=k_{1} * c E C V$.

where $\Delta$ wECV represents the body fluid overload (FO); $\Delta c E C V$ represents calf excess fluid volume which can be approximately represented by $\mathrm{k}_{2}$ in the unit of $\mathrm{L}$.

$$
\begin{aligned}
& \Delta w E C V=k_{1}^{*}\left(k_{2} \exp \left[-\Delta C N R^{n}\right]\right) \\
& F O=K^{*} \exp \left[-\left(C N R_{P}-C N R_{H}\right)^{n}\right],
\end{aligned}
$$

where $\mathrm{CNR}_{\mathrm{P}}$ and $\mathrm{CNR}_{\mathrm{H}}$ represents measurements in patients and at the threshold of a healthy population respectively, $\mathrm{K}$ is a constant $\left(\mathrm{K}=\mathrm{k}_{1} * \mathrm{k}_{2}\right)$ in unit of $\mathrm{L}$, and $\mathrm{n}$ is a non-dimensional constant. The values of $\mathrm{K}$ and $\mathrm{n}$ are obtained by calibration using experimental data.

The normal fluid status (DW) can be calculated by determining the difference between post $\mathrm{HD}$ weight $\left(\mathrm{Wt}_{\mathrm{PostHD}}\right)$ and $\mathrm{FO}$ as follows:

$$
D W=W t_{\text {PostHD }}-F O .
$$

\section{References}

$\checkmark 1$ Kooman JP, van der Sande FM, Leunissen KM: Wet or dry in dialysis - can new technologies help? Semin Dial 2009;22:9-12.

2 Dou Y, Zhu F, Kotanko P: Assessment of extracellular fluid volume and fluid status in hemodialysis patients: current status and technical advances. Semin Dial 2012;25:377-387.

3 Kotanko P, Levin NW, Zhu F: Current state of bioimpedance technologies in dialysis. Nephrol Dial Transplant 2008;23:808-812.

4 Piccoli A: Identification of operational clues to dry weight prescription in hemodialysis using bioimpedance vector analysis. The Italian Hemodialysis-Bioelectrical Impedance Analysis (HD-BIA) Study Group. Kidney Int 1998; 53:1036-1043.

5 Chamney PW, Wabel P, Moissl UM, Muller MJ, Bosy-Westphal A, Korth O, Fuller NJ: A whole-body model to distinguish excess fluid from the hydration of major body tissues. Am J Clin Nutr 2007;85:80-89.

-6 Zhu F, Kuhlmann MK, Kotanko P, Seibert E, Leonard EF, Levin NW: A method for the estimation of hydration state during hemodialysis using a calf bioimpedance technique. Physiol Meas 2008;29:S503-S516.

7 Kuhlmann MK, Zhu F, Seibert E, Levin NW: Bioimpedance, dry weight and blood pressure control: new methods and consequences. Curr Opin Nephrol Hypertens 2005; 14:543549.

8 Kyle UG, Bosaeus I, De Lorenzo AD, Deurenberg P, Elia M, Gomez JM, Heitmann BL, KentSmith L, Melchior JC, Pirlich M, Scharfetter H, Schols AM, Pichard C: Bioelectrical impedance analysis - part I: review of principles and methods. Clin Nutr 2004;23:1226-1243.

$\checkmark 9$ Davies SJ, Davenport A: The role of bioimpedance and biomarkers in helping to aid clinical decision-making of volume assessments in dialysis patients. Kidney Int 2014;86: 489-496.

10 Onofriescu M, Hogas S, Voroneanu L, Apetrii M, Nistor I, Kanbay M, Covic AC: Bioimpedance-guided fluid management in maintenance hemodialysis: a pilot randomized controlled trial. Am J Kidney Dis 2014;64:111118.

11 Wabel P, Chamney P, Moissl U, Jirka T: Importance of whole-body bioimpedance spectroscopy for the management of fluid balance. Blood Purif 2009;27:75-80.

12 Zhu F, Schneditz D, Wang E, Levin NW: Dynamics of segmental extracellular volumes during changes in body position by bioimpedance analysis. J Appl Physiol 1998;85: 497-504.

13 Carter M, Morris AT, Zhu F, Zaluska W, Levin NW: Effect of body mass index (BMI) on estimation of extracellular volume (ECV) in hemodialysis (HD) patients using segmental and whole body bioimpedance analysis. Physiol Meas 2005;26:S93-S99.

14 Abbas SR, Liu L, Sipahioglu MH, Rosales L, Carter M, Kotanko P, Levin NW, Zhu F: Comparison of bioimpedance techniques to detect changes in fluid status in hemodialysis patients. Blood Purif 2014;37:48-56.

15 Liu L, Zhu F, G Raimann J, Thijssen S, Sipahioglu MH, Wystrychowski G, Kitzler T, Tetta C, Wabel P, Kotanko P, Levin NW: Determination of fluid status in haemodialysis patients with whole body and calf bioimpedance techniques. Nephrology (Carlton) 2012;17: 131-140.

16 Tattersall J: Bioimpedance analysis in dialysis: state of the art and what we can expect. Blood Purif 2009;27:70-74.
17 Sarkar SR, Kuhlmann MK, Khilnani R, Zhu F, Heymsfield SB, Kaysen GA, Levin NW: Assessment of body composition in long-term hemodialysis patients: rationale and methodology. J Ren Nutr 2005;15:152-158.

18 Zhu F, Leonard EF, Levin NW: Body composition modeling in the calf using an equivalent circuit model of multi-frequency bioimpedance analysis. Physiol Meas 2005;26:S133-S143.

19 Zhu F, Kotanko P, Handelman GJ, Raimann JG, Liu L, Carter M, Kuhlmann MK, Seibert E, Leonard EF, Levin NW: Estimation of normal hydration in dialysis patients using whole body and calf bioimpedance analysis. Physiol Meas 2011;32:887-902.

20 Patterson R, Ranganathan C, Engel R, Berkseth $\mathrm{R}$ : Measurement of body fluid volume change using multisite impedance measurements. Med Biol Eng Comput 1988;26:33-37.

21 Thomas BJ, Ward LC, Cornish BH: Bioimpedance spectrometry in the determination of body water compartments: accuracy and clinical significance. Appl Radiat Isot 1998;49:447-455.

22 Cox-Reijven PL, Kooman JP, Soeters PB, van der Sande FM, Leunissen KM: Role of bioimpedance spectroscopy in assessment of body water compartments in hemodialysis patients. Am J Kidney Dis 2001;38:832-838.

23 Kyle UG, Bosaeus I, De Lorenzo AD, Deurenberg P, Elia M, Manuel Gomez J, Lilienthal Heitmann B, Kent-Smith L, Melchior JC, Pirlich M, Scharfetter H, M W J Schols A, Pichard C: Bioelectrical impedance analysis part II: utilization in clinical practice. Clin Nutr 2004;23:1430-1453.

24 Hoenich NA, Levin NW: Can technology solve the clinical problem of 'dry weight'? Nephrol Dial Transplant 2003;18:647-650. 